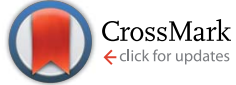

Cite this: J. Anal. At. Spectrom., 2015 30, 642

Received 31st October 2014 Accepted 17th February 2015

DOI: 10.1039/c4ja00386a

www.rsc.org/jaas

\section{Micro-XANES study on Mn browning: use of quantitative valence state maps}

\author{
Gert Nuyts, $^{\text {*a }}$ Simone Cagno, ${ }^{\text {ab }}$ Simone Bugani ${ }^{c}$ and Koen Janssens ${ }^{a}$
}

Historical glass, especially non-durable medieval glass, can undergo corrosion. This sometimes results in the formation of dark-coloured manganese-rich inclusions that reduce the transparency of the glass. While unaltered bulk glass contains manganese mainly present in the +ll valence state, inside the inclusions $\mathrm{Mn}$ is present in higher valence states (+III to +IV). Two different strategies may be considered by conservators when aiming to improve the transparency. One is based on the reduction of highly oxidised black/brown compounds using mildly reducing solutions, while the other focuses more on the extraction of manganese from the inclusions by the application of chelating agents. In this paper, a method for quantitative mapping of the Mn speciation inside partially corroded historical windowpanes based on X-Ray Absorption Near-Edge Structure (XANES) spectroscopy is discussed. The calibration of such $\mathrm{Mn}$ valence state maps based on the combo method, a fairly reliable way to determine the oxidation state, is described in more detail. This method is used to evaluate the effect of reducing treatments on historical glass, dated to the 14th century and originating from Sidney Sussex College (Cambridge, UK), suffering from Mn browning. Glasses were examined by means of Synchrotron Radiation (SR) based microscopic X-Ray Absorption Near-Edge Structure ( $\mu$ XANES) spectroscopy and microscopic X-Ray Fluorescence ( $\mu \mathrm{XRF}$ ). X-Ray elemental distribution maps of glass cross-sections are recorded at different energies, while $\mathrm{Mn} \mathrm{K}$-edge spectra are used to convert these into $\mathrm{Mn}$ valence state (VS) maps. Such valence state maps will allow evaluation of a reducing treatment.

\section{Introduction}

Historical glass, including windowpanes from existing stainedglass windows or fragments encountered in an archaeological context, is often affected by so-called darkening or browning. This phenomenon is caused by the development of dark coloured $\mathrm{Mn} / \mathrm{Fe}$-rich zones in the alteration layer; these zones or plugs $^{1}$ will henceforth be referred to as Mn inclusions. ${ }^{2}$ Sometimes the formation of such inclusions can lead to a reduced or total loss of transparency of the glass, which has already been reported in the literature for archaeological glass excavated from different Northern European sites. ${ }^{3-11}$

A brief summary of the different chemical transformations involved in the weathering of historical silicate glass is given below; a more detailed description can be found elsewhere. ${ }^{9}$ Generally the weathering of silicate glass is induced by the presence of water. ${ }^{\mathbf{1 2}}$ As a first step, molecular water penetrates into the glass via diffusion and/or reversible hydrolysis/

${ }^{a}$ Department of Chemistry, University of Antwerp, Groenenborgerlaan 171, Antwerp 2020, Belgium. E-mail: gert.nuyts@uantwerpen.be; Fax: +323 26532 33; Tel: +323 2653326

${ }^{b}$ CERAD, Norwegian University of Life Sciences, P.O. Box 5003, Ås 1432, Norway ${ }^{c}$ Department of Medical and Surgical Sciences, University of Bologna, Via Massarenti 9 , Bologna 40138, Italy condensation reactions. As a result the silica network will undergo structural transformations: ${ }^{13-15}$

$$
\begin{aligned}
& \equiv \mathrm{Si}-\mathrm{O}-\mathrm{Si} \equiv+\mathrm{H}_{2} \mathrm{O}_{(\mathrm{aq})} \rightarrow 2 \equiv \mathrm{Si}-\mathrm{O}-\mathrm{H} \\
& 2 \equiv \mathrm{Si}-\mathrm{O}-\mathrm{H} \rightarrow \equiv \mathrm{Si}-\mathrm{O}-\mathrm{Si} \equiv+\mathrm{H}_{2} \mathrm{O}_{(\mathrm{aq})}
\end{aligned}
$$

In a second step, an ion exchange process will take place between protons from the environment and cations present within the glass network. ${ }^{\mathbf{1 6 , 1 7}}$ This will mainly take place at low $\mathrm{pH}$ values and will result in the leaching out of most mobile cations (i.e., monovalent $\mathrm{Na}^{+}$and $\mathrm{K}^{+}$). During this process the density of the leached layer will decrease since heavier metal cations are being replaced by lighter protons. On the glass surface, weathering products (i.e., sulfates and chlorides of $\mathrm{Mg}$, $\mathrm{Ca}$, etc.) can be formed. ${ }^{7,18-20}$

$$
\equiv \mathrm{Si}-\mathrm{O}^{-} \mathrm{M}_{\text {(glass) }}{ }^{+}+\mathrm{H}_{(\mathrm{aq})}{ }^{+} \rightarrow \equiv \mathrm{Si}-\mathrm{O}^{-} \mathrm{H}_{\text {(glass) }}{ }^{+}+\mathrm{M}_{(\mathrm{aq})}{ }^{+}
$$

Local $\mathrm{pH}$ can increase when the water in contact with the glass surface is not regularly replenished, due to the ongoing ion exchange. Hydroxyl ions will attack the silica network and cause further damage, this is a process that mainly takes place when the $\mathrm{pH}$ rises above $9 .^{9}$ 


$$
\begin{gathered}
\equiv \mathrm{Si}-\mathrm{O}-\mathrm{Si} \equiv+\mathrm{OH}_{(\mathrm{aq})}{ }^{-} \rightarrow \equiv \mathrm{Si}-\mathrm{O}-\mathrm{H}+\equiv \mathrm{Si}-\mathrm{O}^{-} \\
2 \equiv \mathrm{Si}-\mathrm{O}-\mathrm{H} \rightarrow \equiv \mathrm{Si}-\mathrm{O}-\mathrm{Si} \equiv+\mathrm{H}_{2} \mathrm{O}_{(\mathrm{aq})}
\end{gathered}
$$

The aforementioned steps will cause the formation of a leached layer, a cation-depleted silica network with a lower structural strength and density compared to the original bulk glass as well as a different expansion coefficient. These material properties can result in crack formation.

As described elsewhere in more detail, ${ }^{9}$ when an internal or external manganese source is available, manganese inclusions can be formed inside the leached layer. Historical glass often contains a small amount of manganese (typically $0.4-0.8 \% \mathrm{w} / \mathrm{W}$ when expressed as $\mathrm{MnO}^{\mathbf{2 1}}$ with $\mathrm{Mn}$ (II) being the predominant species. Manganese can be present in the glass as an impurity of the starting materials ${ }^{22,23}$ or can be added deliberately as pyrolusite $\left(\mathrm{MnO}_{2}\right)$, a decolourising agent. ${ }^{11}$ Alternatively, manganese can also be introduced into the glass from the soil in which the glass is buried as dissolved Mn(II). ${ }^{2,11,24,25}$ Previous experiments have indicated the presence of $\mathrm{MnO}_{2}$ in the $\mathrm{Mn}$ inclusions ${ }^{9}$ and a hypothesis for their formation was proposed: in the presence of water and oxygen, $\mathrm{Mn}$ (II) and/or Mn(III) ions can be oxidised to higher oxidation states giving rise to, for example, insoluble $\left(\mathrm{MnO}_{2}\right)$ that can precipitate, a process favoured in alkaline conditions. Several of these Mn compounds that can be formed are characterised by dark brown and black colours. ${ }^{6}$

In glass conservation it is not generally desired to recover glass transparency of Mn-darkened glass fragments via any non-reversible treatment, since a glass conservator's main objective is the conservation of original (glass) material and the prevention of further decay with minimal intervention. ${ }^{\mathbf{2 6}}$ However in a limited number of cases a non-reversible treatment method may be considered, e.g. in extreme cases of darkening where the original colour of the glass and other signs of its history such as applied paint or design on the surface can no longer be appreciated. Two different strategies are known for removing the darkening effect induced by manganese: one is based on the reduction of the highly oxidised black/brown compounds and the other focuses more on the extraction of this element from the inclusions by the application of chelating agents. ${ }^{\mathbf{1 1} 27}$ Since darkening can be caused by numerous highly oxidised Mn compounds, ${ }^{6}$ most of which have a typical black/brown colour, retrieving information on the Mn (average) valence state before and after treatment plays a key role in its evaluation. A first attempt at mapping the Mn speciation was made by us; based on socalled "chemical species-specific sensitivity factors" and under the assumption that only $\mathrm{Mn}$ (II) and $\mathrm{Mn}$ (Iv) are present, distribution maps of the latter were obtained. In this paper, instead, quantitative (average) valence state maps were obtained by recording X-Ray elemental distribution maps of a glass cross-section at different energies, while Mn K-edge spectra are used to convert these into Mn valence state (VS) maps displaying the average valence state. Such maps can then successfully be used in evaluating different reducing treatments on glass suffering from manganese browning.

\section{Materials and methods}

\subsection{Materials and treatments}

All glass fragments used in this study are part of a larger series that originate from an excavation at a former Franciscan friary in the premises of the cathedral of Canterbury, UK and are dated to the 14th century. Since the context data of the excavation was lost, the heritage value of these fragments is limited. ${ }^{28}$ These glasses were of interest, since they were subjected to weathering in a wet environment and visually evidenced extensive $\mathrm{Mn}$ browning. The major components of the original glasses were determined by Scanning Electron Microscopy-Energy Dispersive X-Ray (SEM-EDX) analysis and are summarised in Table 1. For this purpose a JEOL 6300 scanning electron microscope equipped with an energy dispersive X-Ray detector was used. The spectra were collected for 100 seconds by using a $2 \mathrm{nA}$ electron beam current, an accelerating voltage of $20 \mathrm{kV}$ and a microscope magnification of 500. These parameters were found to be suitable for quantitative analysis of glass without significant diffusion of sodium during the irradiation. ${ }^{29}$ The net intensities were calculated with the program AXIL (Analysis of X-Rays by Iterative Least squares $)^{30}$ and quantified by means of a standardless ZAF program. $^{29}$ The cause of the extensive weathering can be explained by the low-silica and high-potash content. ${ }^{31}$ All analysed glass fragments were physically cut, embedded in acrylic resin (Struers, VersoCit-2@) and polished. The resin helps to preserve the sample integrity during polishing. Three different reducing treatments are examined in this study. All applied reducing treatments are performed on the embedded crosssection and are summarised in Table 2.

\subsection{Data collection and processing}

X-Ray Fluorescence (XRF) mapping and X-Ray Absorption NearEdge Structure (XANES) measurements were performed at the European Synchrotron Radiation Facility (ESRF, Grenoble, France), at beamline ID21 with an undulator insertion device. ${ }^{32}$ The storage ring operating conditions were $6 \mathrm{GeV}$ electron energy with a $200 \mathrm{~mA}$ electron current and a 7/8 multibunch operating mode. For these experiments a Si (111) fixed-exit double-crystal monochromator was used, with an energy resolution of $10^{-4}(\Delta E /$ $E)$. A metallic Mn-reference foil $(5 \mu \mathrm{m})$ was used to provide an accurate energy calibration (first inflection point of the Mn-K edge set at $6539 \mathrm{eV}$ ). An upstream Ni mirror was used to remove the high-energy harmonics from the incident beam. All samples were measured in fluorescence mode. The fluorescence intensity was recorded with the sample positioned at $62^{\circ}$ with respect to the incoming beam and using a Silicon Drift Diode XFlash 5100 (Bruker, Germany), with an energy resolution $\approx 160 \mathrm{eV}$, at an angle of $49^{\circ}$ with respect to the sample, resulting in a $69^{\circ}$ angle between the incoming beam and the detector. Fresnel zone plate focusing optics were used, allowing a minimal beamsize of $1.13 \times$ $0.80 \mu \mathrm{m}^{2}$. XRF maps were recorded using a fully focused beam with a $100 \mathrm{~ms}$ acquisition time per pixel and all spectra were evaluated using the PyMCA software package. ${ }^{33}$ In order to minimise beam-induced sample alteration XANES spectra were collected under slightly defocused conditions (see 3.1) from $20 \mathrm{eV}$ 
Table 1 Bulk composition of the used glass samples, presented as oxide concentrations $(\% \mathrm{w} / \mathrm{w})$

\begin{tabular}{lllllllllllll}
\hline Glass type & $\mathrm{Na}_{2} \mathrm{O}$ & $\mathrm{MgO}$ & $\mathrm{Al}_{2} \mathrm{O}_{3}$ & $\mathrm{SiO}_{2}$ & $\mathrm{P}_{2} \mathrm{O}_{5}$ & $\mathrm{SO}_{3}$ & $\mathrm{Cl}$ & $\mathrm{K}_{2} \mathrm{O}$ & $\mathrm{CaO}^{2}$ & $\mathrm{TiO}_{2}$ & $\mathrm{MnO}^{2} \mathrm{Fe}_{2} \mathrm{O}_{3}$ \\
\hline 1 & 3.0 & 8.7 & 1.6 & 52.5 & 3.3 & 0.1 & 0.3 & 11.5 & 16.6 & 0.3 & 1.6 & 0.6 \\
2 & 0.4 & 4.9 & 0.8 & 48.2 & 1.4 & 0.2 & $<$ d.l. & 17.9 & 23.6 & 0.4 & 1.6 & 0.6 \\
\hline
\end{tabular}

Table 2 Summary of all the applied treatment methods

\begin{tabular}{llll}
\hline Sample & Glass type & Treatment & Treatment time \\
\hline A & 2 & Cotton drenched in $5 \% \mathrm{NH}_{2} \mathrm{OH}$ & $24 \mathrm{~h}$ \\
B & 1 & $5 \% \mathrm{NH}_{2} \mathrm{OH}+\mathrm{KCl}+\mathrm{NaCl}$ & $30 \mathrm{~min}$ \\
$\mathrm{C}$ & 1 & $5 \%$ citric acid $\mathrm{pH} 7 \mathrm{buffer}$ & $30 \mathrm{~min}$ \\
\hline
\end{tabular}

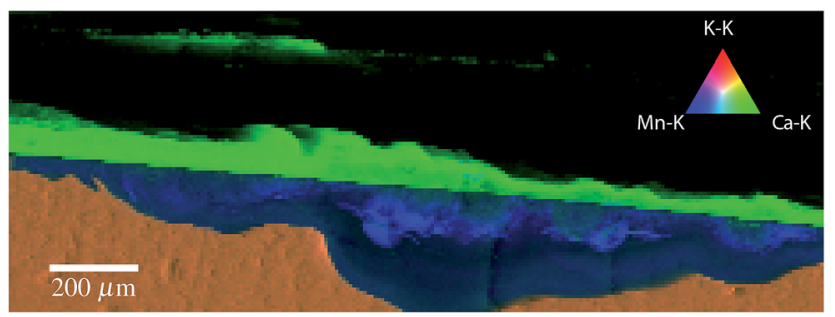

Fig. $1 \mathrm{~K}$ (red), $\mathrm{Ca}$ (green) and $\mathrm{Mn}$ (blue) elemental distribution maps of a cross-section of sample $A\left(1.84 \times 0.67 \mathrm{~mm}^{2}\right)$.

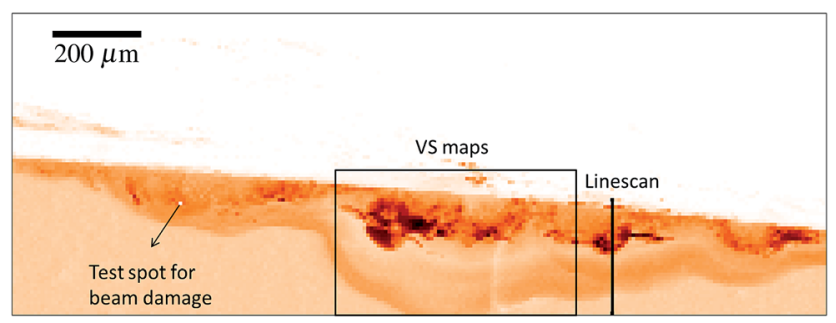

Fig. 2 Mn distribution map of a cross-section of sample A $(1.84 \times 0.67$ $\mathrm{mm}^{2}$ ), darker areas indicate a higher $\mathrm{Mn}$ fluorescence intensity.

below to $90 \mathrm{eV}$ above the Mn-K edge (6520-6630 eV), with $0.73 \mathrm{eV}$ steps for the entire region. A $100 \mathrm{~ms}$ integration time was used at each energy step resulting in around $30 \mathrm{~s}$ measuring time per XANES spectrum. For all XANES spectra, the normalisation was performed by means of the software package ATHENA. ${ }^{34}$ An edgestep normalisation was performed by linear pre-edge subtraction and by regression of a (in general) quadratic polynomial beyond the edge..$^{34}$ Analysis of the recorded XANES spectra was performed by linear combination fitting of the spectra with known reference spectra, using the so-called "combo" method. In this method, spectra are fitted with a published database of pure-valence species recorded by Manceau ${ }^{35}$ (pyrolusite, ramsdellite, $\mathrm{Ca}_{2} \mathrm{Mn}_{3} \mathrm{O}$, $\mathrm{KBi}\left(\mathrm{K}_{0.296}{ }^{+}\left(\mathrm{Mn}_{0.926}^{4+}(\mathrm{vac})_{0.074}\right) \mathrm{O}_{2} \cdot 0.40 \mathrm{H}_{2} \mathrm{O}\right)$, groutite, feitknechtite, manganite, $\mathrm{Mn}_{2} \mathrm{O}_{3}, \mathrm{MnPO}_{4}$, hureaulite, $\mathrm{Mn}^{2+}$-sorbed fungi, rhodocrosite, manganosite, pyroxmangite, tephroite, $\mathrm{MnSO}_{4(\mathrm{aq})}$, $\mathrm{MnSO}_{4(\mathrm{~s})}$; as a result the $\mathrm{Mn}$ species is not identified, but a contribution of each valence state is obtained in a quantitative

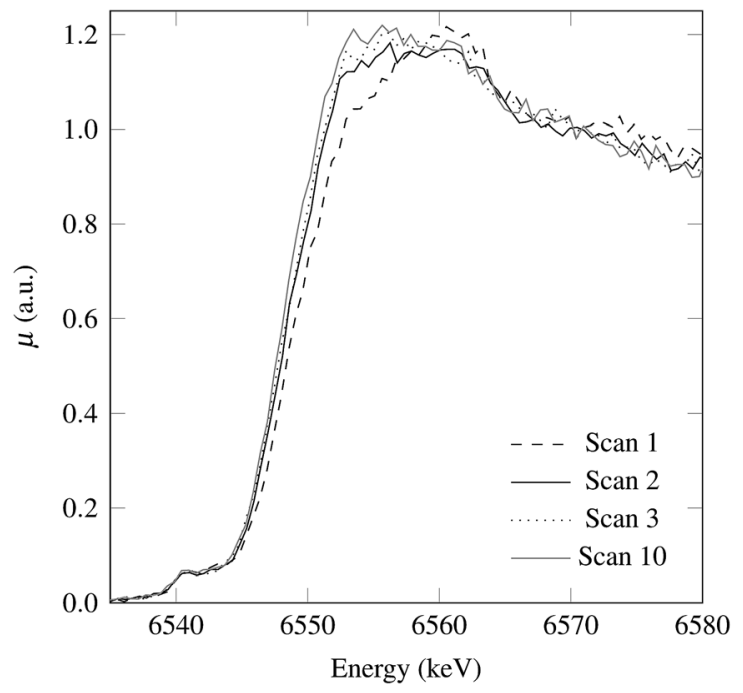

Fig. 3 Repetitive XANES spectra recorded at the same point inside a $\mathrm{Mn}$ inclusion on a cross-section of sample A (Fig. 2).

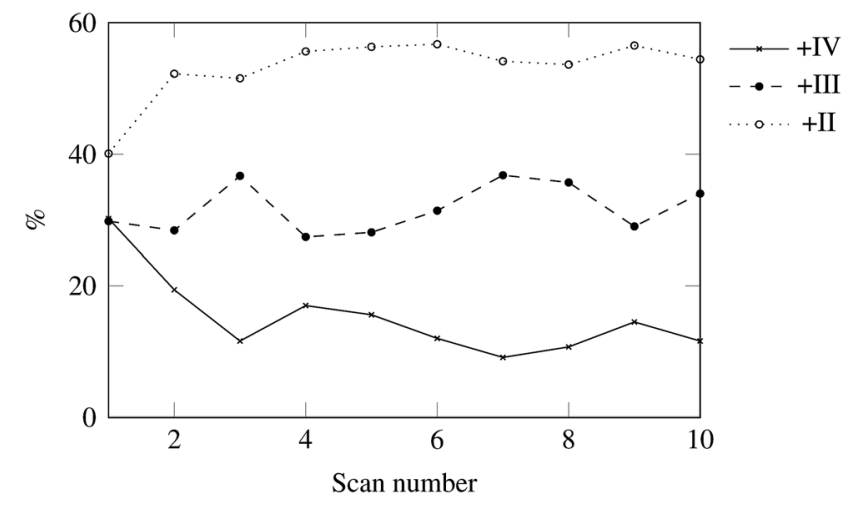

Fig. 4 Relative contributions of $M n(I I), M n(I I)$ and $M n(I V)$ as a function of the radiation time, obtained by fitting ten repetitive XANES spectra using the combo method.

manner. More information on this method, the pure valence references and their data acquisition is provided elsewhere. ${ }^{35}$ The transferability of the database was checked by comparing the spectra of pyrolusite and $\mathrm{Mn}_{2} \mathrm{O}_{3}$, recorded in transmission with an unfocused beam, with those provided by the database.

\section{Results}

\subsection{Photoreduction}

Beam damage caused by ionising radiation is a known and described phenomenon in literature. ${ }^{36}$ Photoredox reactions 


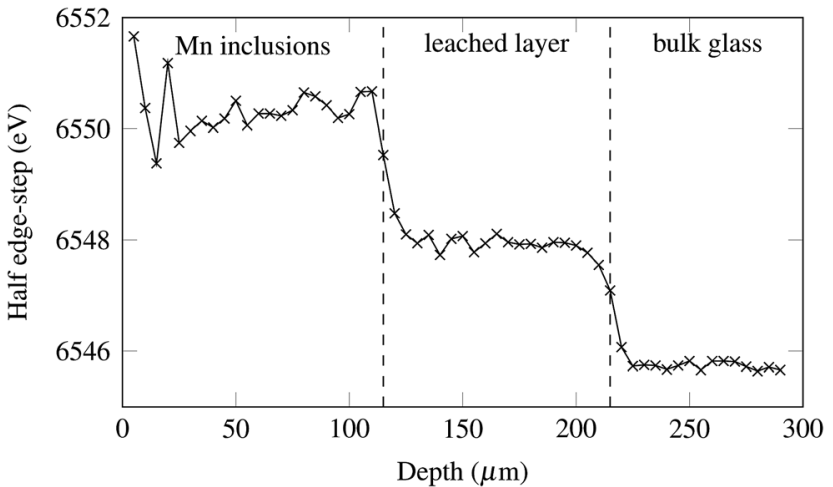

Fig. 5 The edge energy at half edge-step as a function of the depth inside sample $A$.

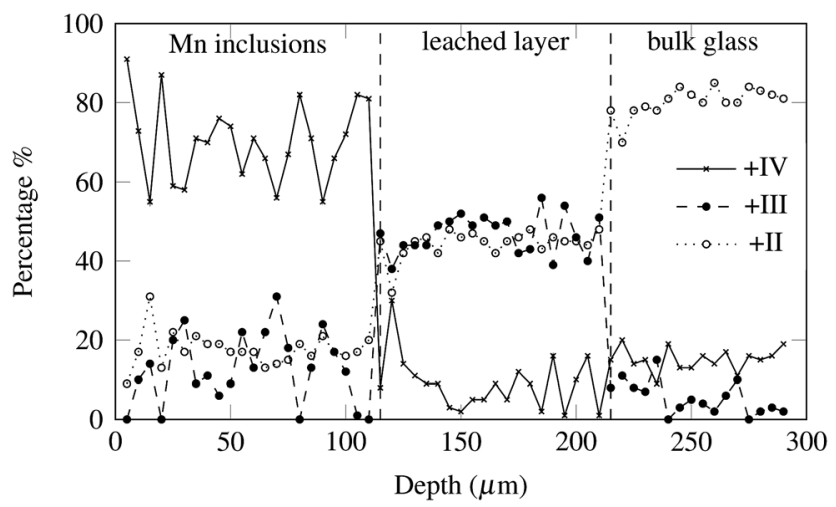

Fig. 6 The relative contribution of all valence states as a function of the depth inside sample $A$.

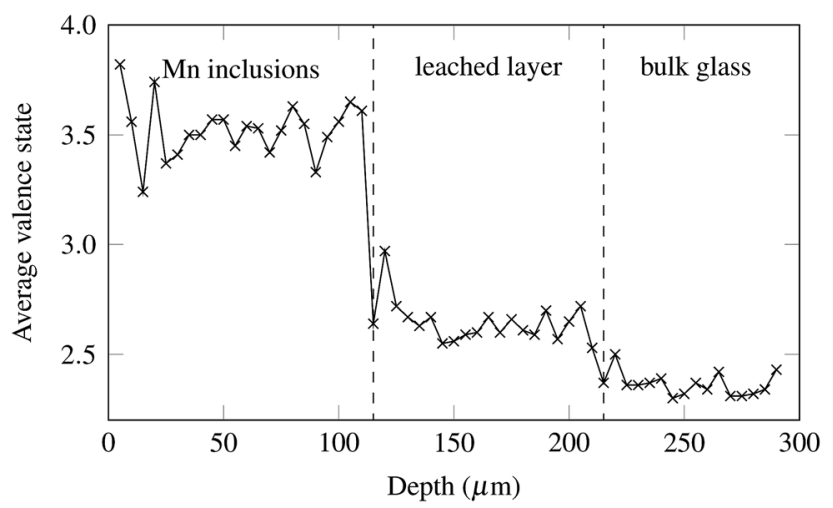

Fig. 7 The average valence state as a function of the depth inside sample A.

induced by a focused X-Ray beam can take place either by water photo-chemistry ${ }^{37,38}$ or direct chemical action, e.g. in nucleic acids the latter accounts for one third. For transition metal ions photoreduction is predominant, ${ }^{39,40}$ while photoreduction with Mn inside an alteration layer was already observed by us in previous research at ESRF with very similar incoming radiation. ${ }^{8}$ In case of poorly crystallised phyllomanganates ${ }^{41}$ they are

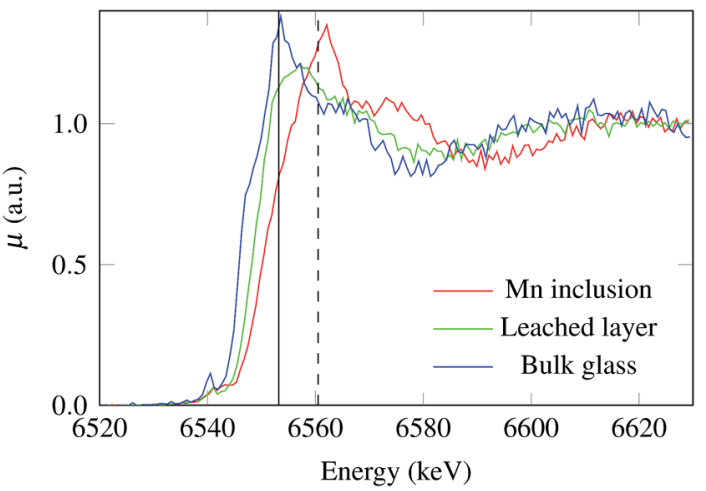

Fig. 8 XANES spectra from the Mn enrichment, leached layer and bulk glass. $E_{1}(6553.2 \mathrm{eV})$ and $E_{2}(6560.5 \mathrm{eV})$ are marked by a solid and dashed line respectively.

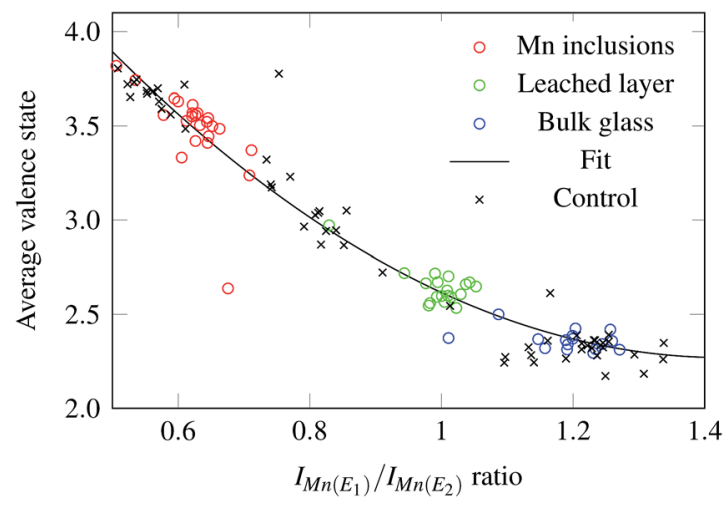

Fig. 9 Correlation between the ratio of the fluorescence intensity at the two energies and the average valence state.

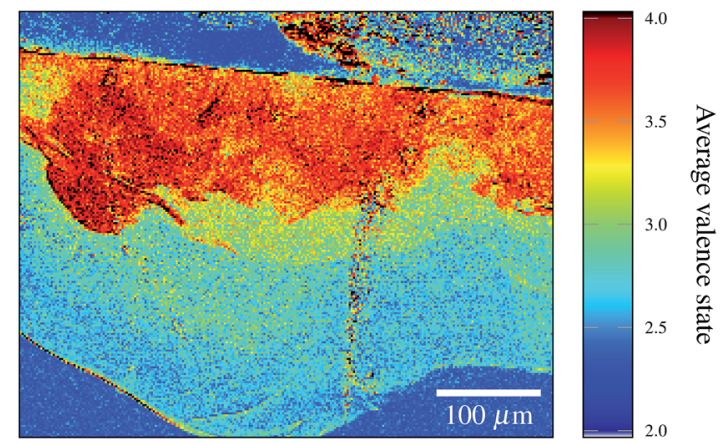

Fig. 10 Mn valence state map of a cross-section of sample A $(512 \times$ $343 \mu \mathrm{m}^{2}$ ).

described as being reduced in a two step process, ${ }^{35}$ during which $\mathrm{Mn}(\mathrm{Iv})$ is first reduced to $\mathrm{Mn}$ (III) and further reduces to $\mathrm{Mn}(\mathrm{II})$. Manceau et $a .^{35}$ suggested that only one electron is transferred at a time and that the reduction from $\mathrm{Mn}$ (III) to $\mathrm{Mn}(\mathrm{II})$ is rate limiting.

In our experiments, tests were performed on sample A prior to its treatment to evaluate the influence of beam damage in the present context of $\mathrm{Mn}$-species mapping in stained glass 


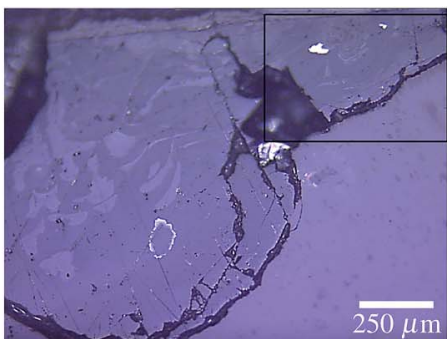

(a)

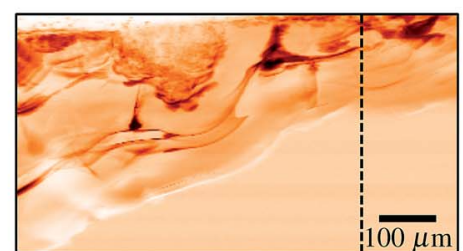

(b)

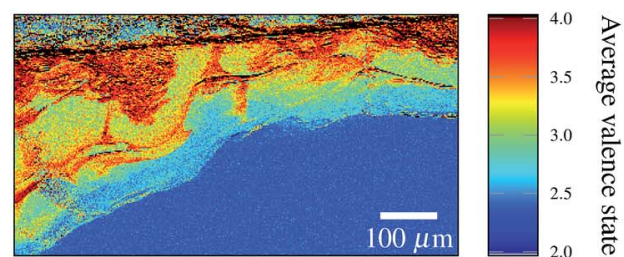

(c)

Fig. 11 Cross-section of sample B before treatment. (a) Optical microscopy picture in reflected light $\left(1.5 \times 1.1 \mathrm{~mm}^{2}\right)$. The black frame marks the area of the valence state mapping. (b) Mn distribution map $\left(780 \times 421 \mu \mathrm{m}^{2}\right)$, darker areas indicate a higher Mn fluorescence intensity. The dashed line marks the right border of the black frame in (a). (c) Mn valence state map $\left(780 \times 421 \mu \mathrm{m}^{2}\right.$ ).

samples. First an XRF map was recorded on a cross-section, which allows to discriminate all the different phases present. An RGB map is presented in Fig. 1, showing the most relevant elemental distributions in glass weathering; namely Mn (blue), $\mathrm{K}$ (red) and $\mathrm{Ca}$ (green). As mentioned in the introduction the leached layer is characterised by a lower $\mathrm{K}$ and $\mathrm{Ca}$ content in comparison to the bulk and contains $\mathrm{Mn}$ enrichments or inclusions. On top of the original glass surface Ca salts are deposited in the course of the alteration process. Mn inside an inclusion was already proven to be more prone to beam damage ${ }^{8}$ compared to $\mathrm{Mn}$ present in the bulk glass. Based on the Mn elemental distribution a suitable spot was chosen inside a Mn inclusion (Fig. 2) on which 10 repetitive XANES spectra (27 $\mathrm{s}$ per spectrum) were recorded, using a fully focused beam (1.13 $\left.\times 0.80 \mu \mathrm{m}^{2}\right)$. Photoreduction is clearly present during the first three spectra (Fig. 3), evidenced by a shift of the edge-energy to lower values, and additionally a change is observed in the shape of the spectrum. By fitting all spectra using the combo method ${ }^{35}$ it is possible to obtain for each spectrum the relative contribution of each of the valence states (+II, +III and +IV) as a function of the scan number (Fig. 4). Photoreduction was observed during the during first three XANES scans. After one scan $\pm 30 \%$ of the Mn was present as $\mathrm{Mn}$ (Iv), $\pm 30 \%$ as $\mathrm{Mn}$ (III) and $\pm 40 \%$ as $\mathrm{Mn}$ (II). After the third scan a $15 \%$ decrease of $\mathrm{Mn}$ (IV) is observed, while Mn(II) increases by the same amount and Mn(III) remains constant. These results indicate that either $\mathrm{Mn}(\mathrm{Iv})$ is directly reduced to $\mathrm{Mn}$ (II) or a two-step process takes place with approximately equal rates, in contrast to the findings of Manceau et al. ${ }^{35}$ For all further XANES measurements performed during these experiments, photoreduction was minimised by using a slightly defocused beam $\left(8 \times 8 \mu \mathrm{m}^{2}\right)$. Should photoreduction occur, Mn(II) will be overestimated and most probably Mn(III) or (IV) will not be detected or quantified properly. Photoreduction was evaluated by recording the fluorescence intensity at $6553 \mathrm{eV}$ as a function of the radiation time. For a fully focused beam a $17 \%$ increase was observed, which was only $5 \%$ in the case of a slightly defocused beam. Further defocusing did not lead to any significant changes in beam damage. On the other hand, for the collection of the XRF maps, a fully focused beam was employed, since only $100 \mathrm{~ms}$ dwell time was used for each pixel.

\subsection{Energy calibration curve}

Prior to any treatment a XANES linescan was recorded on a cross-section of sample A (Fig. 2), with a step-size of $5 \mu \mathrm{m}$ over a total span of $290 \mu \mathrm{m}$. It is well known that the "edge energy" (e.g. energy at half edge-step) of most transition elements shifts, qualitatively, to higher energies, increasing the oxidation state. For this reason many authors have used it as an indication of the Mn valence. ${ }^{42-45}$ In Fig. 5 this energy across the linescan is plotted and three regions with markedly different speciation can readily be observed. By comparing these to Fig. 2 they are in accordance with the different phases present in historically weathered glass, namely the bulk glass (blue), the leached layer

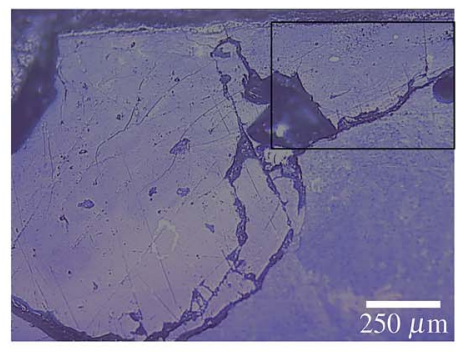

(a)

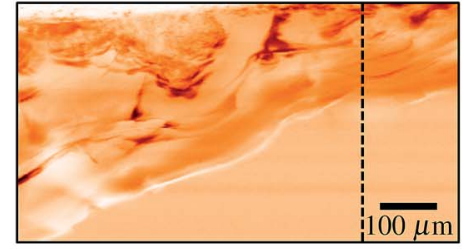

(b)

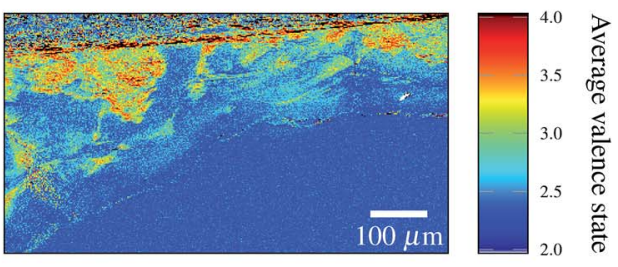

(c)

Fig. 12 Cross-section of sample B after treatment. (a) Optical microscopy picture in reflected light $\left(1.5 \times 1.1 \mathrm{~mm}^{2}\right)$. The black frame marks the area of the valence state mapping. (b) Mn distribution map $\left(780 \times 421 \mu \mathrm{m}^{2}\right)$, darker areas indicate a higher Mn fluorescence intensity. The dashed line marks the right border of the black frame in (a). (c) Mn valence state map $\left(780 \times 421 \mu \mathrm{m}^{2}\right.$ ). 


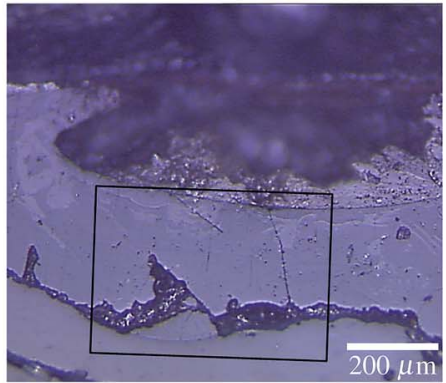

(a)

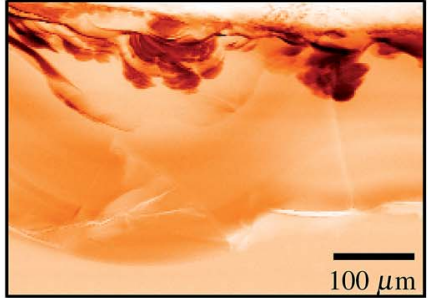

(b)

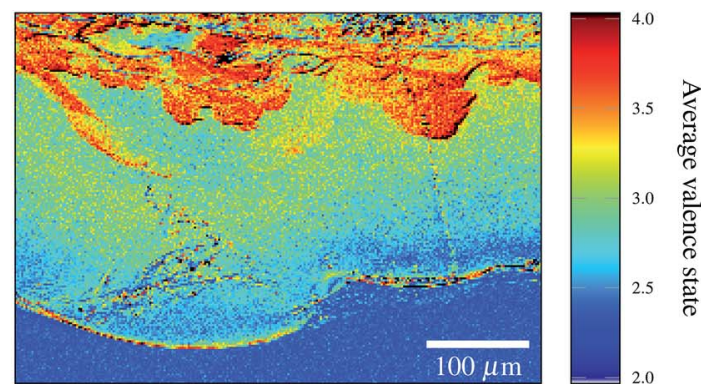

(c)

Fig. 13 Cross-section of sample $C$ before treatment. (a) Optical microscopy picture in reflected light $\left(1.0 \times 0.8 \mathrm{~mm}^{2}\right)$. The black frame marks the area of the valence state mapping. (b) Mn distribution map $\left(520 \times 364 \mu \mathrm{m}^{2}\right)$, darker areas indicate a higher Mn fluorescence intensity. (c) Mn valence state map $\left(512 \times 347 \mu \mathrm{m}^{2}\right)$.

(green) and the Mn inclusions (red). Although the edge energy holds qualitative information concerning the Mn valence state, Farges et al. $^{46}$ state that it can lead to an error of up to $90 \%$. Therefore all spectra are fitted using the combo method, and the relative contributions of all valence states (Fig. 6) and the average valence state (Fig. 7) are obtained and can be plotted against the depth inside the glass. $\mathrm{Mn}$ is present in the bulk mainly as $\mathrm{Mn}$ (II) with a smaller contribution of $\mathrm{Mn}$ (IV) and $\mathrm{Mn}$ (III) resulting in an average valence state of 2.4. Close to the original glass surface a $110 \mu \mathrm{m}$ thick Mn enriched zone (known as Mn inclusions) is present, in which the Mn speciation is considerably more heterogeneous in comparison to the bulk glass. In these inclusions $\mathrm{Mn}$ is mainly present as $\mathrm{Mn}$ (Iv), with a contribution ranging from $55 \%$ to $90 \%$. More importantly, inside the $100 \mu \mathrm{m}$ thick leached layer situated between the original glass surface and the bulk glass, the Mn speciation is different to that of the inclusions. An equal contribution of $\mathrm{Mn}$ (II) and $\mathrm{Mn}$ (III) is observed here, resulting in an average valence state of 2.6, while the homogeneity is comparable to that of the bulk glass.

Although a XANES linescan offers some insight into the Mn speciation and enables to discriminate the different phases present, it may not be representative for the entire weathered layer. This can be circumvented by recording X-Ray distribution maps at different energies. The ratio between the X-Ray fluorescence intensities recorded at different energies contains information about the average valence state. Based on the difference in XANES response of the various Mn species, the most suitable energies are chosen. Fig. 8 shows three normalised XANES spectra recorded during the linescan of sample A, each being representative for each of the $\mathrm{Mn}$ phases. The largest difference is found in the energies of the white-line of $\mathrm{Mn}$ in bulk glass $\left(E_{1}=6553.2 \mathrm{eV}\right)$ and of the white-line energy of $\mathrm{Mn}$ in the enrichment $\left(E_{2}=6560.5 \mathrm{eV}\right)$. This ratio $I_{\mathrm{Mn}\left(E_{1}\right)} / I_{\mathrm{Mn}\left(E_{2}\right)}$ was also calculated for all normalised XANES spectra acquired during the linescan at the two given energies and plotted against the average valence state obtained by the combo method (Fig. 9) when fitting the same spectra. In Fig. 9 the datapoints are visualised according to the phase they originate from, namely Mn inclusions (red circles), leached layer (green circles) and bulk glass (blue circles). A clear correlation is observed between the ratio $I_{\mathrm{Mn}\left(E_{1}\right)} / I_{\mathrm{Mn}\left(E_{2}\right)}$ and the average valence state (VS); by least-square fitting using a 2nd degree polynomial eqn (1) was obtained, which describes the best fitted parabola.

From samples B and C similar linescans were recorded before and after treatment; due to the high noise level the resulting XANES spectra were averaged per phase. Together with

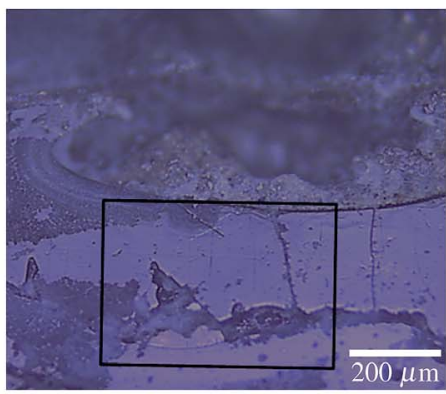

(a)

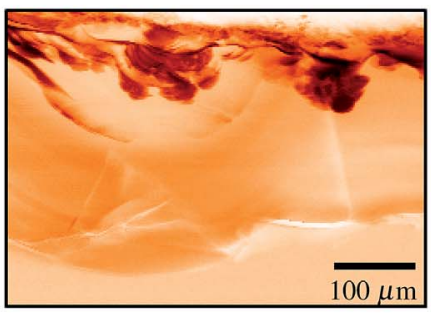

(b)

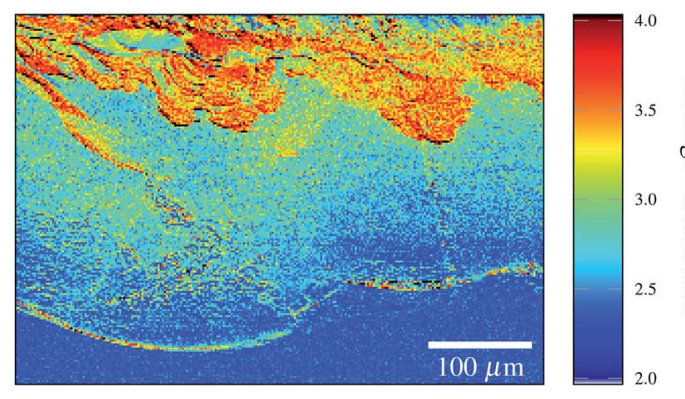

(c)

Fig. 14 Cross-section of sample $C$ after treatment. (a) Optical microscopy picture in reflected light $\left(1.0 \times 0.8 \mathrm{~mm}^{2}\right)$. The black frame marks the area of the valence state mapping. (b) Mn distribution map $\left(520 \times 364 \mu \mathrm{m}^{2}\right)$, darker areas indicate a higher Mn fluorescence intensity. (c) Mn valence state map $\left(510 \times 347 \mu \mathrm{m}^{2}\right)$. 


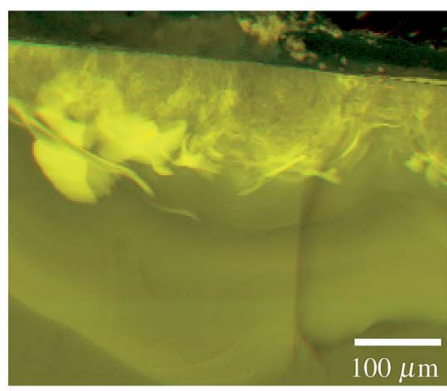

(a)

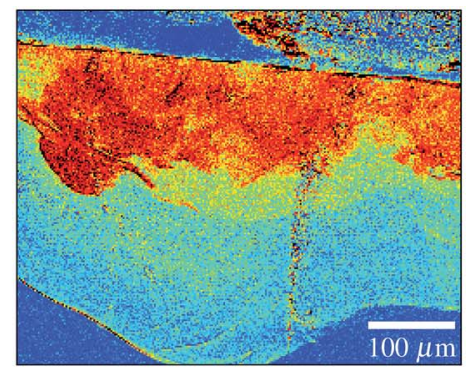

(b)

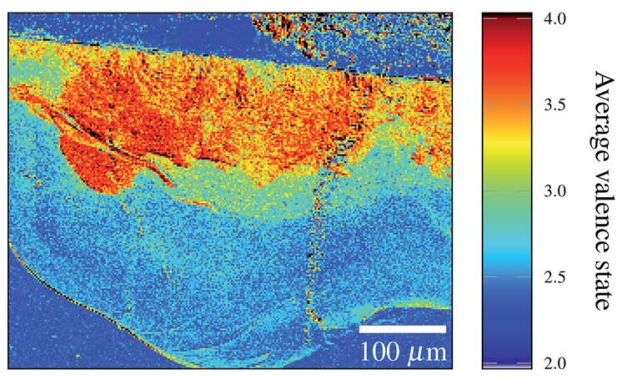

(c)

Fig. 15 Cross-section of sample A. (a) Elemental distribution map of Mn before (green) and after (red) $\left(512 \times 347 \mu \mathrm{m}^{2}\right)$. (b) Mn valence state map before treatment $\left(512 \times 343 \mu \mathrm{m}^{2}\right)$. (c) Mn valence state map after treatment $\left(510 \times 347 \mu \mathrm{m}^{2}\right)$.

a linescan of sample A after treatment these averaged spectra could then be used as control datapoints (black crosses in Fig. 9) to validate the obtained correlation. The validity of the calibration relation allows us to indeed use only two energies for valence state mapping. A $I_{\mathrm{Mn}\left(E_{1}\right)} / I_{\mathrm{Mn}\left(E_{2}\right)}$ ratio map can easily be obtained by dividing the two Mn distribution maps recorded at these energies. It is necessary to eliminate any influence from variations in the primary beam intensity. Therefore each $\mathrm{Mn}$ elemental distribution needs to be normalised by the primary beam intensity $\left(I_{0}\right)$ or the ratio map needs to by multiplied by the inverse ratio of the primary beam intensities $I_{0\left(E_{2}\right)} / I_{0\left(E_{1}\right)}$. This ratio can accurately be determined by the ratio $I_{\mathrm{Ca}\left(E_{2}\right)} / I_{\mathrm{Ca}\left(E_{1}\right)}$, since the XRF response of $\mathrm{Ca}$ can be considered constant in the range between $E_{1}$ and $E_{2}$; the Ca K edge energy (4038 eV) is almost $2.5 \mathrm{keV}$ lower than the Mn K edge energy (6539 eV). Using eqn (1) these $I_{\operatorname{Mn}\left(E_{1}\right)} / I_{\operatorname{Mn}\left(E_{2}\right)}$ ratio maps can then be converted into valence state maps. Pixels with an average valence state lower then 0 or higher then 4 were set to 0 and 4 respectively, this never exceeded $6 \%$ of the total number of pixels. Such maps were calculated for three stained glass samples to be subjected to different conservation methods (see Table 2 and Fig. 11c, 13c and 15b). A leached layer with an average valence state between 2.5 and 3 is found in all three maps, clearly different from the $\mathrm{Mn}$ inclusions, which have an average valence state between 3 and 4 or the bulk glass with an average valence state around 2.4. When considering the homogeneity of the Mn speciation, the conclusions are in good accordance with those retrieved from a single XANES linescan discussed in Fig. 5-7. While the bulk glass is homogeneous, Mn inside the inclusions shows a more heterogeneous distribution.

$$
\widehat{\mathrm{VS}}=1.88\left(\frac{I_{\mathrm{Mn}\left(E_{1}\right)}}{I_{\mathrm{Mn}\left(E_{2}\right)}}\right)^{2}-5.37 \frac{I_{\mathrm{Mn}\left(E_{1}\right)}}{I_{\mathrm{Mn}\left(E_{2}\right)}}+6.1
$$

\subsection{Evaluation of reducing treatments}

Since valence state maps such as that shown in Fig. 10 display the average valence state in each pixel, they allow to examine the influence, in terms of Mn speciation, of treatment methods on glass suffering from manganese browning. Three different treatment methods (Table 2) were tested in the presented experiments, all of which are based on the reduction of highly oxidised Mn compounds to more water soluble Mn. Next to looking at the valence state maps, it is evidently possible to check Mn removal or diffusion by the treatment by comparing elemental distribution maps before and after treatment at the same energy.

Hydroxylamine hydrochloride was used as a reducing agent in the first treatment test. The effect of such a reducing treatment is dual: as hydroxylamine itself is oxidised, it reduces the dark coloured Mn oxides to Mn(II), thus removing the darkening. In addition Mn(II) has a higher solubility in water, which allows Mn diffusion/removal. With this aim sample B was immersed in a $5 \% \mathrm{w} / \mathrm{w} \mathrm{NH}_{2} \mathrm{OH} \cdot \mathrm{HCl}$ solution for 30 minutes. Already when observing the treated, cross-sectioned sample with an optical microscope in reflected light, the results of the treatment can be observed. Fig. 11a displays an untreated crosssection of sample B: in reflected light, the unaltered bulk glass is observed as more white and the leached layer as more grey. In addition the cracks formed during the glass-alteration process and sample manipulation, and $\mathrm{Mn}$ inclusions, with a tone comparable to the bulk glass, can be distinguished. After treatment these inclusions can no longer be observed (Fig. 12a). When comparing the Mn distribution maps before and after treatment (Fig. 11b and 12b), it becomes clear that this is indeed not due to complete $\mathrm{Mn}$ removal. The higher mobility of $\mathrm{Mn}$ (II) does allow diffusion and clearly a limited amount of $\mathrm{Mn}$ is removed, mainly in the inclusions, but most is still present after the treatment. However the Mn valence state map of sample B after treatment (Fig. 12c) indicates that most of the Mn which originally had a valence greater than 3 is effectively reduced, thus explaining the removal of the darkening effect.

In a second treatment sample C was immersed in $5 \% \mathrm{w} / \mathrm{w}$ citric acid with buffer solution $(\mathrm{pH} 7)$. From the optical microscopy images before and after treatment (Fig. 13a and 14a) it already becomes clear that, using this treatment, unwanted side-effects occur as the leached layer and bulk glass show additional cracking. Most likely this is due to additional leaching followed by rapid drying of the sample. Due to these cracks it is difficult to visually evaluate the effectiveness of the treatment in removing the darkening effect. The effect of such cracks on XRF is only minor, thus Mn valence state mapping remains possible and Fig. 14c shows a decrease in the more red 
areas (+IV) visible in Fig. 13c, mainly in the Mn inclusions but not as extensive as with the treatment using hydroxylamine hydrochloride. A similar effect is observed inside the leached layer, where some regions are found after treatment to have an average valence state comparable to the bulk glass. Since almost no $\mathrm{Mn}$ is reduced during the treatment, little or no Mn diffusion/removal (Fig. 13b and 14b) is observed.

Complete immersion of glass panes into a treatment solution is evidently not possible with larger window panes and lacks spatial selectivity. In glass conservation and restoration, therefore, more local treatment methods are preferentially employed, e.g. by applying cotton drenched in a treatment solution to the area on the window pane; in that manner only the areas suffering from manganese browning are treated and no additional damage to unaltered bulk glass will be induced. A similar treatment method was evaluated here (cotton drenched in $5 \% \mathrm{w} / \mathrm{w}$ hydroxylamine hydrochloride); in order to evaluate the influence of the treatment on all different Mn speciation areas that are present, the cotton swab was brought into contact with a cross-sectioned surface where it would normally be applied on the corroded surface. As can be seen from Fig. 15c, after a treatment time of $24 \mathrm{~h}$ hours the effect is similar to the immersion in $5 \% \mathrm{w} / \mathrm{w}$ citric acid treatment: little or no $\mathrm{Mn}$ removal is observed but the $\mathrm{Mn}$ that is present is clearly reduced.

\section{Discussion and conclusions}

Two topics were discussed in this paper: namely photoreduction and the use of quantitative Mn valence state maps in the evaluation of treatment methods on historically weathered glass suffering from Mn staining/browning. Prior to X-Ray experiments it was crucial to obtain measuring conditions during which no damage is induced by the primary X-Ray beam. In this paper photoreduction of $\mathrm{Mn}$ inside the glass alteration layer due to a focused X-Ray beam $\left(1.13 \times 0.80 \mu \mathrm{m}^{2}\right)$ was studied, by recording several consecutive XANES spectra at one point inside the alteration layer. Photoreduction was observed during the first three XANES spectra. It was demonstrated that either Mn(IV) directly reduces to Mn(II) or a two step process with equal rates takes place. To the authors' best knowledge, for the first time quantitative $\mathrm{Mn}$ valence state maps were obtained, by conversion of ratio maps $I_{\mathrm{Mn}\left(E_{1}\right)} / I_{\mathrm{Mn}\left(E_{2}\right)}$ using a calibration curve. The latter was obtained by fitting Mn K-edge XANES spectra taken across the alteration layer with pure valence references (combo method) and associating the resulting Mn-valence state values with the local "two energy" intensity ratio. Such valence state maps showed that $\mathrm{Mn}$ inside the leached layer has a speciation clearly different from that of the bulk glass, but more importantly, different from that of the inclusions. In the leached layer, manganese has a average valence state of 2.6, corresponding to equal contributions of $\mathrm{Mn}$ (II) and $\mathrm{Mn}$ (III), while $\mathrm{Mn}$ in the inclusions has an average valence state of 3.5 (or higher), indicating the presence of a mixture of $\mathrm{Mn}$ (IV) and Mn in lower valence states in the sampled volume.

In addition to the characterisation of all phases present in historically weathered glass, $\mathrm{Mn}$ valence state maps could usefully be employed for the comparison of different reducing treatments of glass suffering from manganese browning. Since the browning effect is mainly caused by the presence of higher oxidised Mn compounds, obtaining information concerning the valence state before and after treatment is essential. In this paper three different treatment methods were evaluated. Two samples were immersed into a reducing solution of $5 \% \mathrm{w} / \mathrm{w}$ hydroxylamine hydrochloride and $5 \% \mathrm{w} / \mathrm{w}$ citric acid for $30 \mathrm{~min}$. The hydroxylamine proved to be the most effective in reducing the highly oxidised Mn compounds in the inclusions, a change that could be observed visually and was supported by $\mathrm{Mn}$ valence state mapping. In the case of the immersion in citric acid, visual observations were impeded by additional damage (cracking) caused by the treatment itself; most likely due to additional leaching followed by rapid drying of the sample. However Mn valence state maps did show a minor reduction taking place, mainly inside the inclusions. Since reduction of insoluble higher oxidised $\mathrm{Mn}$ compounds to more soluble Mn(II) enables Mn diffusion/removal, this was only observed after the immersion in hydroxylamine. In contrast to immersion into a treatment solution, a more realistic treatment method was evaluated in a similar manner. A glass cross-section was put into contact with cotton drenched in 5\% w/w hydroxylamine hydrochloride for a period of $24 \mathrm{~h}$. The results were similar to those obtained by the citric acid treatment, but with lesser additional damage to the surrounding glass.

\section{Acknowledgements}

This research was supported by the Interuniversity Attraction Poles Programme Belgian Science Policy (IUAP VI/16) and partially by the Research Council of Norway through its Centres of Excellence funding scheme, project number 223268/F50. The text also presents results of Center of Excellence AGRECHEM (Research Fund University of Antwerp, Belgium) and from the Fund for Scientific Research (FWO, Brussels, Belgium) projects no. G.0C12.13 and G.01769.09. We gratefully acknowledge ESRF for granting beamtime (experiment EC768) and the beamline scientists of ID21 for their support. The authors also want to thank Leonie Seliger of Canterbury Cathedral, UK, the Sidney Sussex College Council and Bursar Charles Larkum for providing the archaeological samples of the Franciscan Friary which are kept in store for Sidney Sussex College in Cambridge (UK).

\section{References}

1 H. Roemich, S. Gerlach, P. Mottner, F. Mees, P. Jacobs, D. van Dyck and T. Carbo, Scientific Basis For Nuclear Waste Management XXVI, 506 Keystone Drive, Warrendale, PA 15088-7563 USA, 2003, pp. 97-108.

2 A. Domenech-Carbo, M. Domenech-Carbo and L. OseteCortina, Electroanalysis, 2001, 13, 927-935.

3 M. Schreiner, Mikrochim. Acta, 1991, 2, 255-264.

4 W. Muller, M. Torge and K. Adam, Glass Sci. Technol., 1994, 67, 45-48. 
5 W. Muller, M. Torge and K. Adam, Glass Sci. Technol, 1995, 68, 285-292.

6 D. Watkinson, L. Weber and K. Anheuser, Archaeometry, 2005, 47, 69-82.

7 M. Domenech-Carbo, A. Domenech-Carbo, L. Osete-Cortina and M. Sauri-Peris, Microchim. Acta, 2006, 154, 123-142.

8 S. Cagno, G. Nuyts, S. Bugani, K. De Vis, O. Schalm, J. Caen, L. Helfen, M. Cotte, P. Reischig and K. Janssens, J. Anal. At. Spectrom., 2011, 26, 2442-2451.

9 O. Schalm, K. Proost, K. De Vis, S. Cagno, K. Janssens, F. Mees, P. Jacobs and J. Caen, Archaeometry, 2011, 53, 103-122.

10 H. Wouters, G. Nuyts, S. Cagno, N. Minten, W. Meulebroeck, K. Baert, H. Terryn, K. Janssens, H. Thienpont and K. Nys, Integrated Approaches To The Study of Historical Glass IAS12, 1000 20th St, Po Box 10, Bellingham, WA 982270010, USA, 2012.

11 R. G. Newton and S. Davison, Conservation of glass, Butterworth-Heinemann, Linacre House, Jordan Hill, Oxford OX2 8DP, UK, 1989.

12 R. Conradt, J. Am. Ceram. Soc., 2008, 91, 728-735.

13 B. Bunker, J. Non-Cryst. Solids, 1994, 179, 300-308.

14 R. Doremus, Earth Planet. Sci. Lett., 1998, 163, 43-51.

15 J. Sterpenich and G. Libourel, Chem. Geol., 2001, 174, 181193.

16 H. Scholze, J. Non-Cryst. Solids, 1982, 52, 91-103.

17 M. Melcher and M. Schreiner, Anal. Bioanal. Chem., 2004, 379, 628-639.

18 M. Schreiner, G. Woisetschlager, I. Schmitz and M. Wadsak, J. Anal. At. Spectrom., 1999, 14, 395-403.

19 G. Woisetschlager, M. Dutz, S. Paul and M. Schreiner, Mikrochim. Acta, 2000, 135, 121-130.

20 M. Melcher and M. Schreiner, J. Non-Cryst. Solids, 2006, 352, 368-379.

21 E. Sayre, Advances in Glass Technology, 1963, part 2, pp. 263282.

22 M. Misra, K. Ragland and A. Baker, Biomass Bioenergy, 1993, 4, 103-116.

23 W. Stern and Y. Gerber, Archaeometry, 2004, 46, 137-156.

24 G. Cox and B. Ford, J. Mater. Sci., 1993, 28, 5637-5647.

25 A. Silvestri, G. Molin and G. Salviulo, J. Non-Cryst. Solids, 2005, 351, 1338-1349.

26 Corpus Vitrearum MediiAevi, Guidelines for the Conservation and Restoration of Stained Glass, http:/www.cvma.ac.uk/ conserv/guidelines.html, 2004, accessed 16 January 2015.

27 S. Fitz, A new method of cleaning browned medieval glass, 1981.

28 D. Hind, I. Marsden and C. Evans, Cambridge Archaeological Unit, Report no. 106, 1994.

29 O. Schalm and K. Janssens, Spectrochim. Acta, Part B, 2003, 58, 669-680.
30 P. V. Espen, K. Janssens and J. Nobels, Chemometrics and Intelligent Laboratory Systems, 1986, vol. 1, pp. 109-114.

31 K. Hellemans, A. Vincke, S. Cagno, D. Herremans, W. De Clercq and K. Janssens, J. Archaeol. Sci., 2014, 47, 121-133.

32 M. Salome, M. Cotte, R. Baker, R. Barrett, N. Benseny-Cases, G. Berruyer, D. Bugnazet, H. Castillo-Michel, C. Cornu, B. Fayard, R. Gagliardini, E. az nd Hino, J. Morse, E. Papillon, E. Pouyet, C. Rivard, V. A. Sole, J. Susini and G. Veronesi, 11th International Conference on Synchrotron Radiation Instrumentation (SRI 2012), Dirac House, Temple Back, Bristol BS1 6BE, England, 2013.

33 V. A. Sole, E. Papillon, M. Cotte, P. Walter and J. Susini, Spectrochim. Acta, Part B, 2007, 62, 63-68.

34 B. Ravel and M. Newville, Phys. Scr., T, 2005, 115, 1007-1010. 35 A. Manceau, M. A. Marcus and S. Grangeon, Am. Mineral., 2012, 97, 816-827.

36 G. N. George, I. J. Pickering, M. J. Pushie, K. Nienaber, M. J. Hackett, I. Ascone, B. Hedman, K. O. Hodgson, J. B. Aitken, A. Levina, C. Glover and P. A. Lay, J. Synchrotron Radiat., 2012, 19, 875-886.

37 B. Garrett, D. Dixon, D. Camaioni, D. Chipman, M. Johnson, C. Jonah, G. Kimmel, J. Miller, T. Rescigno, P. Rossky, S. Xantheas, S. Colson, A. Laufer, D. Ray, P. Barbara, D. Bartels, K. Becker, H. Bowen, S. Bradforth, I. Carmichael, J. Coe, L. Corrales, J. Cowin, M. Dupuis, K. Eisenthal, J. Franz, M. Gutowski, K. Jordan, B. Kay, J. LaVerne, S. Lymar, T. Madey, C. McCurdy, D. Meisel, S. Mukamel, A. Nilsson, T. Orlando, N. Petrik, S. Pimblott, J. Rustad, G. Schenter, S. Singer, A. Tokmakoff, L. Wang, C. Wittig and T. Zwier, Chem. Rev., 2005, 105, 355-389.

38 A. K. El Omar, U. Schmidhammer, P. Jeunesse, J.-P. Larbre, M. Lin, Y. Muroya, Y. Katsumura, P. Pernot and M. Mostafavi, J. Phys. Chem. A, 2011, 115, 12212-12216.

39 M. C. Corbett, M. J. Latimer, T. L. Poulos, I. F. Sevrioukova, K. O. Hodgson and B. Hedman, Acta Crystallogr., Sect. D: Biol. Crystallogr., 2007, 63, 951-960.

40 S. V. Antonyuk and M. A. Hough, Biochim. Biophys. Acta, Proteins Proteomics, 2011, 1814, 778-784.

41 J. Bargar, B. Tebo, U. Bergmann, S. Webb, P. Glatzel, V. Chiu and M. Villalobos, Am. Mineral., 2005, 90, 143-154.

42 A. Manceau, A. Gorshkvo and V. Drits, Am. Mineral., 1992, 77, 1133-1143.

43 J. Bargar, B. Tebo and J. Villinski, Geochim. Cosmochim. Acta, 2000, 64, 2775-2778.

44 D. McKeown and J. Post, Am. Mineral., 2001, 86, 701-713.

45 D. McKeown, W. Kot, H. Gan and I. Pegg, J. Non-Cryst. Solids, 2003, 328, 71-89.

46 F. Farges, Phys. Rev. B: Condens. Matter Mater. Phys., 2005, 71, 155109-1-155109-14. 